Texas A\&M University-San Antonio

Digital Commons @ Texas A\&M University-San Antonio

Special Education Faculty Publications

College of Education and Human Development

$11-2019$

\title{
Effects of Cross-Age Tutors With EBD for Kindergarteners At Risk of Mathematics Difficulties
}

\author{
Gavin W. Watts \\ Texas A\&M University-San Antonio, gavin.watts@tamusa.edu \\ Diane Pedrotty Bryant \\ University of Texas at Austin \\ Garrett J. Roberts \\ University of Denver
}

Follow this and additional works at: https://digitalcommons.tamusa.edu/sped_faculty

Part of the Science and Mathematics Education Commons, and the Special Education and Teaching Commons

\section{Repository Citation}

Watts, Gavin W.; Bryant, Diane Pedrotty; and Roberts, Garrett J., "Effects of Cross-Age Tutors With EBD for Kindergarteners At Risk of Mathematics Difficulties" (2019). Special Education Faculty Publications. 6.

https://digitalcommons.tamusa.edu/sped_faculty/6

This Article is brought to you for free and open access by the College of Education and Human Development at Digital Commons @ Texas A\&M University- San Antonio. It has been accepted for inclusion in Special Education Faculty Publications by an authorized administrator of Digital Commons @ Texas A\&M University- San Antonio. For more information, please contact deirdre.mcdonald@tamusa.edu. 


\section{Journal of Emotional and Behavioral Disorders}

\section{Effects of Cross-Age Tutors with EBD for Kindergarteners At-risk for Mathematics Difficulties}

\begin{tabular}{|r|l|}
\hline Journal: & Journal of Emotional and Behavioral Disorders \\
\hline Manuscript ID & JEBD-05-2019-047.R1 \\
\hline Manuscript Type: & Original Manuscript \\
\hline Keyword: & $\begin{array}{l}\text { mediated procedures < Peer(s), math < Instruction, Positive behavioral } \\
\text { supports, academic < Interventions, behavioral < Interventions }\end{array}$ \\
\hline \multicolumn{2}{|l}{} \\
\hline
\end{tabular}


Effects of Cross-Age Tutors with EBD for Kindergarteners At-risk for Mathematics Difficulties

\begin{abstract}
Challenges with numerical proficiency at an early age can lead to substantial gaps in learning and are associated with detrimental long-term outcomes. Additionally, students with emotional-behavioral disorders (EBD) can have some of the most challenging behavioral and academic needs to address. The purpose of this study was to identify the effects and collateral outcomes of utilizing cross-age tutors (i.e., older students) with/at-risk for EBD to deliver a number line board game intervention to kindergarten students at-risk for mathematics disabilities. A multiple baseline design across participants was utilized to evaluate the following research questions: (1) What are the effects of a number line game delivered by a cross-age tutor with EBD on the mathematics performance of kindergarten students with mathematics difficulties? (2) Can students with EBD implement tutoring procedures with fidelity? (3) What are the effects of the cross-age tutoring training and implementation on the tutors' classroom behaviors and risk-status for EBD? Tutoring sessions took place for 25-30 minutes, three times per week, over 10 weeks. Results suggest cross-age tutoring to be an effective and feasible model for improving mathematics performance of kindergarteners atrisk and, to a lesser extent, the behavioral performance of students with EBD.
\end{abstract}

Keywords: emotional-behavioral disorders, cross-age tutoring, mathematics, number line 
Effects of Cross-Age Tutors with EBD for Kindergarteners At-risk for Mathematics Disabilities

Young children with difficulties in mathematics achievement often challenged with basic number sense knowledge and skills (Mazzocco, Feigenson, \& Halberda, 2011).

Students with mathematics difficulties frequently struggle to develop adequate number sense knowledge and skills required to facilitate later fact and computation skills (Locuniak \& Jordan, 2008). Early discrepancies in number competence have been shown to have significant short-term and long-term outcomes for this population (Jordan, Glutting, \& Ramineni, 2010). In the short term, if students are identified with mathematics deficits by age 7 or 8 , it is likely they were correctly identified as being at-risk in kindergarten (Toll, Van der Ven, Kroesbergen, \& Van Luit, 2011). Long-term, students with deficits in early numeracy knowledge and skills show continuing low performance on future measures of mathematics achievement (Jordan, Kaplan, Locuniak \& Ramineni, 2007). Children with low performance in early numeracy knowledge and skill areas may also struggle to develop the conceptual foundations that will support the learning of more advanced mathematics (Van Luit \& Schopman, 2000).

The National Mathematics Advisory Panel (NMAP, 2008) emphasizes the importance of early mathematics interventions, and preventative interventions, that have a strong foundation in whole number concept development and proficiency. Early intervention in these foundational concepts and skills is supported, in an effort to deter long-term deficits and future barriers to learning advanced mathematical concepts (NMAP, 2008). If not addressed effectively, early difficulties in acquiring essential numeracy skills can persist into long-term challenges that may become impervious to intervention (Jordan, Kaplan, Ramineni, \& Locuniak, 2009). One early numeracy intervention with a foundation in whole number concepts is a number line board game, which is based on theoretical frameworks and 
empirical research connections to the mental number line (Laski \& Siegler, 2014). To implement number line board games requires only minimal training time, costs (i.e., materials), and prerequisite mathematics skills (e.g., Ramani, Siegler, \& Hitti, 2012). Considering these accessible requirements, the ease of implementation may allow nonteachers such as older students (i.e., cross-age tutors) to deliver the intervention, with high levels of fidelity, allowing for teachers to arrange smaller instructional groupings of students in need of individualized, explicit instruction (Clarke et al., 2017; Doabler et al., 2017).

\section{Students with EBD as Cross-age Tutors}

The academic and behavioral needs of students with emotional-behavioral disorders (EBD) are some of the most challenging to address (Kern, 2015). Additionally, the high priority placed on special educators' planning and instructional time has demanded a need for instructional techniques that are practical, low- or no-cost, and above all, effective (Bettini, Kimerling, Park, \& Murphy, 2015). With these considerations in mind, special educators may need to focus on underutilized resources within their own schools, such as peers, to provide individualized instruction that meets both academic and behavioral needs. One peermediated model that has shown effectiveness is cross-age tutoring.

Cross-age tutoring utilizes an older student as the more knowledgeable and experienced peer in a coaching or instructional role, called the 'tutor', while the students receiving coaching or instruction from a tutor are called 'tutees'. An increasing research base in cross-age tutoring suggests that it can be an effective model for teaching academic and social skills to students with disabilities (Okilwa \& Shelby, 2010). Blake, Wang, Cartledge, and Gardner (2000) found students with challenging behaviors to be effective instructors of social skills for younger students, with the proper training and supervision. Additionally, these tutors may also obtain collateral academic and/or behavioral skill improvement through 
this role (Watts, Bryant, \& Carroll, 2019). This role may be appropriate for students with

$\mathrm{EBD}$ due to the unique interactions and behavioral requirements that the position facilitates.

Given the academic and behavioral challenges of students with EBD, utilizing cross-age tutoring may provide direct, individualized instruction, as well as provide opportunities for the tutor with EBD to practice and develop social, behavioral, and academic skills in an instructional setting.

\section{Purpose and Research Questions}

To date, cross-age tutoring, with students with EBD as tutors, has been evaluated infrequently in regards to its effectiveness in promoting mathematics skills in the early grades (Watts, Bryant, \& Carroll, 2019). The following research questions guided this study:

(1) What are the effects of a number line board game on the mathematical performance of kindergarten students at-risk for mathematics difficulties, when delivered by older tutors (i.e., 5th-6th graders) with/at-risk for EBD? (2) To what extent can students with EBD effectively serve as cross-age tutors and deliver early numeracy instruction through number line board games, as measured by the fidelity of implementation? (3) What are the effects of the tutor training and implementation of the cross-age model on the tutors' (with EBD) Checkin/Check-out (CICO) behavioral point sheet scores?

\section{Method}

\section{Setting and Participants}

University and school IRB approved all protocols prior to the start of the study. The study took place at a public elementary school in a suburban school district in central Colorado. The school served students in preschool through sixth-grade. School records from 2016 showed that $40.4 \%$ of the students qualified to receive free or reduced-price lunch. All tutor training and tutoring sessions took place in an unoccupied general education classroom. 
Tutees. A kindergarten teacher nominated students based on perceived difficulties in early numeracy knowledge and skills. Students were included if their Test of Early Mathematics Ability-Third Edition (TEMA-3) pre-test score fell below the average standard score range of 90-110 (Ginsburg \& Baroody, 2003). Students currently receiving supplemental support to their business as usual (BAU) mathematics instructional minutes were excluded. Table 1 provides information on the five kindergarten students who participated as tutees (i.e., students receiving instruction from tutors). Across tutees, pre-test results showed a mean standard score of $76.2(S D=2.9$, range $=72-80)$.

Tutors. Fifth- and sixth-grade students qualified as tutors if they had IEPs identifying them as having EBD. The special educator also nominated additional students with disabilities who had challenging classroom behaviors and/or IEP goals directly related to social or behavioral skill development. Students were excluded if they had a history of violent or aggressive behaviors, or daily attendance rates below $90 \%$ during the previous school year. The Student Risk Screening Scale-Internalizing and Externalizing (SRSS-IE; Drummond, 1994; Lane \& Menzies, 2009) was administered at pre-test and post-test and is further described under measures. Students qualified to participate as cross-age tutors if either their externalizing or internalizing score fell within the moderate to high ranges. Table 2 displays tutors' demographic information and pre-test scores.

\section{Measures}

Test of Early Mathematics Ability. A researcher administered the TEMA-3

(Ginsburg \& Baroody, 2003) which served as a pre-test and post-test of mathematics knowledge and skills. The TEMA-3 is a norm-referenced, diagnostic tool for determining mathematical strengths and weaknesses of students, ages 3 through 8, and consists of 72 items in the domains of informal and formal mathematics. Informal items evaluate four 
domains: numbering skills, number-comparison facility, calculation skills, and understanding of concepts. Formal items evaluate numerical literacy, mastery of number facts, calculation skills, and understanding of concepts. Reliability coefficients range from $r=.94$ to .96 , and alternate-form coefficients range from $r=.93$ to .97 . Test-retest reliability coefficients are $r=$ .82 to .93 (Ginsburg \& Baroody, 2003). A trained researcher with a background in special education, and familiar with the TEMA-3 procedures, observed, more than $25 \%$ of the administrations of the TEMA-3 to prospective tutees. A checklist aligned with the scripted prompts of the TEMA-3 measured fidelity of assessment procedures. Mean fidelity of assessment was $97 \%$ (range $=94 \%$ to $100 \%)$.

Student Risk Screening Scale. The elementary school measure is an adapted version of the SRSS (Drummond, 1994), consisting of one subtest for externalizing behaviors (SRSS-E7; 7 items) and one subtest for internalizing behaviors (SRSS-I5; 5 items). All items are rated on a 4-point Likert-type scale. Externalizing subtest (SRSS-E7) cut scores are as follow: low-risk $=$ 0-3 points; moderate-risk $=4-8$ points; and high-risk $=9-21$ points. Internalizing subtest (SRSS-I5) cut scores are as follow: low-risk $=0$-1 points; moderate-risk =2-3 points; and high-risk $=4-15$ points (Lane et al., 2015).

The Texas Early Mathematics Inventory-Aim Checks. The Texas Early Mathematics Inventory-Aim Checks (TEMI-AC; University of Texas System/Texas Education Agency, 2009) were administered weekly, as a progress monitoring tool, to assess tutees' mathematical performance. The validated early numeracy measure contains four subtests: magnitude comparisons, number identification, number sequences, quantity recognition. Each subtest is a 2 min timed assessment. The raw scores for the four subtests are then summed to provide a total score. This assessment has five forms, and measures numerical and operational skills and knowledge, found to be directly related to critical 
numerical competency and early mathematics skills. The TEMI-AC alternate-form

reliability, across five forms, is above .80 . The special educator administered the TEMI-AC following the last tutoring session each week, and during approximately the same time in baseline and maintenance phases.

Check-In/Check-out Point Sheets. CICO behavioral point sheets served as the progress monitoring measure for tutors' classroom behavior. Typically, CICO procedures include components related to teacher-provided attention for participating students, such as providing feedback/reinforcement for behavioral progress on daily CICO sheets (Hawken, Bundock, Kladis, O’Keeffe, \& Barrett, 2014). These components were intentionally omitted in an attempt to control outside influences on potential effects of the tutoring program on classroom behaviors. Thus, the CICO point sheets served solely as a data collection tool to index the social functioning of tutors outside of the tutoring environment. None of the tutors participated in any CICO procedures/programming prior to the intervention. Tutors' classroom teachers (i.e., general education teachers for inclusion classes and a paraprofessional for special education classes) scored CICO sheets after each instructional period. The investigator calculated weekly CICO mean scores and graphed the data accordingly.

The paper-based CICO sheets consist of three behavioral indicators/goals and were scored by classroom teachers on a scale from zero to two points, dependent upon the number of redirections required for a given behavior during the class period. The three behavioral indicators aligned with the school-wide Positive Behavioral Interventions and Supports (PBIS; Sugai \& Horner, 2006) domains within the behavioral expectations matrix: 'be respectful', 'be responsible', and 'be safe'. Each domain consists of PBIS school-wide behavioral expectations and examples, and are taught to the students through PBIS classroom 
lessons throughout the school year.

\section{Social Validity}

After the intervention, tutees, tutors, and teachers completed a researcher-developed social validity questionnaire comprised of 5-point Likert-type scale questions (9 questions for tutors; 8 questions for teachers; 7 questions for tutees). Questions addressed participants' understanding of the program and responsibilities, potential change(s) in students' performance in mathematics/classroom behaviors, self-assessment of participation as tutor/tutee, feasibility/ease of implementation, and whether they would like to participate in future incarnations of the program.

\section{Interscorer Agreement}

The investigator trained the special educator and kindergarten teacher on administration and scoring procedures for the TEMI-AC in a 45 min session. Initial interscorer agreement was calculated on dummy coded, practice TEMI-AC forms at 97.8\% across all forms. Interscorer agreement on student responses was calculated by summing the total number of agreements and dividing by the total number of agreements plus disagreements and multiplying by 100 . Across each phase of the study, interscorer agreement was calculated on a minimum of $25 \%$ of the tests. The mean interscorer agreement across all phases was $98.3 \%$.

The investigator also trained four general education teachers and a special education paraprofessional on CICO scoring procedures. Reliability was assessed through practice scenarios in the natural instructional environment by scoring the class periods immediately following the training session. Interobserver/scorer agreement was calculated by totaling the number of agreements between the teacher and the researcher scores for each behavioral indicator for each student, dividing by the total number of comparisons (i.e., items) and 
multiplying by 100 . Interscorer agreement ranged from $81.8 \%$ to $100 \%$ across all observed class periods $(M=89.6 \%)$.

\section{Research Design and Procedures}

Two sets of concurrent multiple baseline designs (Kennedy, 2005) were implemented to evaluate the effects of the tutoring program on (1) tutees' mathematics performance on weekly progress monitoring measures, and (2) tutors' weekly mean scores on CICO behavioral point sheets. The independent variable for tutees was attending cross-age tutoring sessions in which they participated in number line board games for 25-min per day, 3 days per week, over 10 weeks. The tutors' intervention consisted of two components: (1) tutor training sessions in which the tutor received instruction on tutoring skills, number line board game procedures, and positive behavioral reinforcement strategies; and (2) attendance and implementation of the cross-age tutoring sessions with their tutee.

The number line board games followed the specifications and designs used by Laski and Siegler (2014), where spaces contained numerals 0-100. Teacher training sessions took place during two, 45 min teacher planning periods over two consecutive days. Both the kindergarten and special education teacher were trained on tutoring session supervision roles and responsibilities. The special educator took the role of the lead supervisor of the tutoring sessions due to his familiarity with the tutors and their behavioral needs. Supervision responsibilities included monitoring and supporting individual tutoring dyads (e.g., providing redirection if needed), providing positive reinforcement (e.g., specific verbal praise), and managing the time of the sessions. The kindergarten teacher observed and documented tutors' fidelity of implementation of the tutoring procedures with a fidelity checklist. The investigator conducted interobserver agreement checks and follow-up training sessions with the individual teachers at scheduled times throughout the intervention. 


\section{Baseline Phase}

During the baseline phase, tutors and tutees attended their BAU class schedules. The TEMI-AC was administered to the tutees weekly, at approximately the same time of the school day when future tutoring sessions would be implemented. A special education paraprofessional (for the special education setting) and the general education teacher (for the inclusion setting) completed the tutors' CICO point sheets. This allowed for behavioral ratings to be obtained from teachers who were blind or semi-blind to the study.

\section{Intervention Phase}

Tutor training. Prior to the starting tutoring sessions, each tutor was individually trained on tutoring procedures by the investigator during a 1:1, 45-min training session, which was also observed by the special educator. The tutor training sessions included introducing the number line board game materials, modeling, guided practice, corrective feedback, role-playing tutoring sessions, and evaluating the following skills: (1) instructional techniques and number line board game procedures, (2) corrective feedback methods, and (3) positive behavioral reinforcement strategies. Instructional techniques included: how to greet their tutee, reviewing the previous session (i.e., what went well, what they will focus on improving during the current session), starting the game, keeping their tutee on task, and the number line board game rules and procedures. Training on the number line board game procedures and corrective feedback methods were based upon the training manual developed by Ramani, Siegler, and Hitti (2012) to train paraprofessional for an earlier study. Some of the language used in the training manual was adapted, with the authors' permission, to meet the needs of the elementary student tutors. The corrective feedback method included a twostep process. When the tutee was observed making a counting error, for example, if the tutee's game piece sat on number six and they spun a three on the spinner and they then 
moved their game piece by counting the number of spaces they earned (e.g., "1, 2, 3”)

instead of counting-on from the number their game piece was currently sitting on (e.g., "7, 8, 9'), the tutor would first verbally prompt the tutee to count the numbers on the board game, giving them another practice opportunity. If the tutee again made an error by counting from 'one', or made an error in counting the consecutive numbers correctly, the tutor would model how to count-on correctly, followed by providing another practice opportunity. Positive behavioral reinforcement strategies included providing specific feedback on tutees' counting skills and verbal statements of praise for on-task behaviors.

Fidelity of implementation of tutor training sessions was assessed through a procedural checklist containing the training components aligned with the scripted training manual. A second researcher was trained on the observational measure and IOA was established at greater than $95 \%$ on practice administrations of the training prior to implementation. The second researcher observed $40 \%$ of the tutor training sessions and found the mean quality of implementation to be $96.5 \%$ across sessions.

Tutoring intervention. Tutees attended three tutoring sessions per week in an unoccupied classroom for 10 weeks. Sessions were 25-30 min and supplemental to the tutees' 45 min BAU daily instructional time in mathematics. None of the tutees received additional mathematics beyond the previously stated 45 min of mathematics instruction. Tutees participated in the number line board game with the tutor, one-on-one, with the tutor providing the game procedures, modeling, corrective feedback, and positive reinforcement. After the last tutoring session each the week, tutees were administered a paper-based TEMIAC.

Maintenance. The maintenance phase occurred for four weeks following the conclusion of the last tutoring session. No further tutoring sessions took place between the 
end of the intervention phase and the administration of maintenance measures. To assess maintenance, the TEMI-AC was administered to each of tutees during the typically scheduled tutoring time at 2- and 4-weeks after the final tutoring session. To assess the maintenance of outcomes for the tutors, teachers of the tutors were asked to continue scoring CICO point sheets after each instructional period.

Tutors' fidelity of implementation. The kindergarten teacher assessed fidelity of implementation of tutoring procedures by the cross-age tutors with EBD during each tutoring session. The teacher, trained on the fidelity checklist of tutoring procedures (i.e., modeling, providing practice opportunities, corrective feedback procedures, positive behavioral reinforcement techniques), observed using momentary time-sampling procedures, rotating among each tutor every $30 \mathrm{~s}$. The teacher used a timer, which buzzed, to notify a change to the next interval. IOA was assessed through a second, independent observation of the same tutoring sessions by a trained researcher for more than $30 \%$ of the total fidelity observations conducted during the study. When a tutor's fidelity of implementation of tutoring procedures was observed to fall below an $80 \%$ mean score across a given week, a retraining session on tutoring procedures was provided to the tutor by the investigator immediately prior to the first tutoring session the following week.

\section{Data Analysis}

Results were interpreted based on visual analysis guidelines by the What Works Clearinghouse (WWC) guidelines (Institute of Educational Sciences [IES], 2017) and the Council for Exceptional Children (CEC) Standards for Evidence-Practices in Special Education guidelines (Cook et al., 2014). Both the WWC (IES, 2017) and the CEC (Cook et al., 2014) guidelines recommend visual analysis to identify functional relationships. In visual analysis, three within phase and two between adjacent phase variables determined the 
presence and direction of a functional relationship. The within phase variables included the level (i.e., central tendency; means and standard deviations), the trend or slope, and the range or standard deviation of the data from the trend line. Between adjacent phase variables included immediacy of effect (i.e., following a change in the independent variable how quickly a change in the pattern of the dependent variable occurs) and the degree of overlap (i.e., a proportion of overlap of data points between phases). To measure the degree of overlap, we utilized the percentage of nonoverlapping data (PND) points with a higher percentage indicating a greater effect (Horner, Swaminathan, Sugai, \& Smolkowski, 2012). Each case was individually assessed according to these guidelines.

Study findings. Outcomes were also categorized as strong-, moderate-, or noevidence of a causal relationship based on the quantity of the demonstrations of effect and non-effect (i.e., level, trend, variability, immediacy of effect, PND; IES, 2017). Studies with three or more demonstrations of effect and no non-effect were categorized as strong evidence. Studies with three or more demonstrations of effect and one demonstration of noneffect were categorized as moderate effect. Studies with less than three demonstrations of effect were categorized as no evidence.

\section{Results}

Figure 1 displays tutee weekly TEMI-AC math fluency total scores. Worth noting is that the intervention phase was introduced prior to an identified, stable baseline for some of the later dyads due to time constraints of the study.

\section{RQ1: Mathematics Performance of Tutees}

Figure 1 displays the tutees weekly mathematics fluency outcomes as the total number of items correctly completed across the four, two min subtests. Note, due to the attrition of Tutee 3, Tutor 3 was reverted to baseline phase after the third week of 
intervention (i.e., removed tutoring program attendance/responsibilities). From baseline to intervention phases, all five tutees demonstrated an increase (demonstrating a positive effect) in level and a slight (see tutee 1) to large (see tutees 2, 3, and 4) increase in a positive trend. All tutees had low variability around the trend line in the intervention phase, with tutees 1,2 , and 4 showing no change in variability from baseline to intervention and tutees 3 and 5 showing a decrease in variability from the baseline to intervention phases. Immediacy of effect was not present. Table 3 presents the PND across phases for each participant. The mean PND for intervention phase, compared to the baseline, was $68 \%(S D=34.9$, range: 10 $100 \%)$. The mean PND for maintenance, compared to the baseline, was $100 \%(S D=0 \%)$. For the tutee math fluency outcome, there were more than three demonstrations of effect and no non-effects, suggesting strong evidence of a causal relationship. Additionally, the TEMA3 was administered as a post-test (see Table 4). TEMA-3 pre-test standard scores ranged from 72 to $80(M=76.2, S D=2.9)$. At post-test, tutees scores ranges from 89 to 90 , with a mean score of $93(S D=4.2)$. The mean change in score was $17.8(S D=4.0$, range $=12-21)$.

\section{RQ2: Tutors' Fidelity of Implementation}

Across tutors, the fidelity of implementation mean was $90.5 \%$. Weekly means, across tutors, were above $90 \%$ in seven of ten intervention weeks, and above $80 \%$ in nine of ten intervention weeks. Across tutors, a steady increasing trend was exhibited in weekly fidelity means from Week 1 through Week 5, and then stabilizing above 95\% for each of the remaining weeks of the intervention. Retraining sessions were required for four of five tutors, and all retraining sessions took place within the first 3 weeks of implementation. None of the tutors required a retraining session after the third week of intervention. The interobserver agreement across tutor observations ranged from $88 \%$ to $100 \%(M=92.8 \%)$.

\section{RQ3: Behavioral Outcomes for Tutors}


Figure 2 displays the tutors weekly percentage of points earned on their CICO. For the within phase demonstration of effects, from baseline to intervention phases, all five tutors demonstrated a slight increase (demonstrating a positive effect) in level, with a negative (see tutor 3) to no change (see tutors, 1, 2, 3, and 4) in trend. Tutors had similar variability across phases, with the exception of tutor 2 having greater variability in the intervention phase then the baseline phase. Immediacy of effect was not present. The mean PND for the intervention phase was $65.3 \%$ ( $S D=21.8$, range: $30-90 \%)$. The mean PND for maintenance was $40 \%$ ( $S D$ $=54.8$, range: $0-100 \%$ ). For the tutor CICO outcome, there were less than three demonstrations of effect and more than one non effects, suggesting no evidence of a causal relationship.

All five tutors' post-intervention SRSS-IE scores showed decreased risk-status on both externalizing and internalizing subtests (SRSS-E7 and SRSS-I5). Table 5 displays tutors' pre-/post-test scores and EBD risk-status. Across tutors, externalizing behavior scores showed the greatest improvement, with a mean score decrease from $13.2(S D=2.6)$ to 9.8 $(S D=3.5)$, while internalizing risk scores decreased at lower rates or remained at approximately the same levels. An improvement in risk-categorization was exhibited for two tutors, with a change from high- to moderate-risk status for externalizing behaviors.

\section{Social Validity}

All participants reported high favorability towards the benefit and effectiveness of the intervention $(M=5.0)$. Tutors perceived themselves to have the skills necessary to be effective tutors $(M=4.4)$. Teachers perceived the tutoring program to be successful in increasing tutors' positive behaviors $(M=4.0)$ and decreasing negative/challenging behaviors $(M=4.0)$. Tutors scored themselves similarly in these areas $(M=4.0)$ but their self-ratings in decreasing challenging behaviors were slightly lower $(M=3.8)$. The highest 
ratings, across tutors, tutees, and teachers were in the perception of the intervention's impact on tutees' mathematics skills $(M=4.0 ; 4.75 ; 4.0$, respectively). Additionally, all tutors and tutees reported high agreement regarding their understanding of responsibilities $(M=4.55)$, ease of implementation $(M=4.43)$, and desire to participate in future incarnations of the program $(M=5.0)$. Both teachers reported neutral ratings $(M=3.0)$ for the ease of implementation due to challenges in scheduling tutoring sessions across differing grade level schedules, but high ratings for the program's perceived benefits for all students $(M=5.0)$.

\section{Discussion}

\section{Mathematics Performance of Tutees}

Previous reviews of cross-age instructional models with tutors with EBD have shown consistent, positive effects on mathematics performance of both tutees and tutors (Ryan, Reid, \& Epstein, 2004). Two studies focusing on tutoring early numeracy knowledge and skills showed moderate to large effects in tutee outcomes and large effects in tutor outcomes (Watts, Bryant, \& Carroll, 2019). Similarly, the at-risk kindergarten students in this study showed moderate improvements in early numeracy knowledge and skills, such as counting, number comparison, and number magnitude. In regards to effectiveness, this study's findings are consistent with the literature base showing number line board games as a promising intervention for young children with mathematics difficulties (Ramani, Siegler, \& Hitti, 2012). Additionally, the findings related to tutees' improved mathematics performance add to the evidence-base suggesting number line board games to be an effective instructional tool for promoting early numeracy knowledge and skills for students with at-risk backgrounds (Ramani \& Siegler, 2008; Siegler \& Ramani, 2009).

Previous studies utilizing cross-age tutors with EBD as the interventionists, in delivering mathematics instruction to students at-risk or with disabilities, have shown 
moderate to large effects in improving mathematics performance for tutees when compared to studies utilizing cross-age tutoring for instruction in other content or skill areas (e.g., reading fluency, spelling; Lazerson, 2005; Ryan, Reid, \& Epstein, 2004). One possible explanation may be the structured, procedural steps for some mathematics skills may be more conducive to the cross-age tutoring model than, for example, reading fluency or comprehension skills.

\section{Students with EBD as Cross-age Tutors}

Across the small number of previous studies measuring and reporting fidelity of cross-age tutors with EBD, findings show high implementation rates, ranging from $88 \%$ to 97\% (Blake, Wang, Cartledge, \& Gardner, 2000; Hamelberg, 1987). Additionally, when fidelity is measured for cross-age tutors with EBD, the related outcomes for tutees is typically substantial in academic and behavioral skill improvements. The study at hand found similar results regarding tutors' fidelity of implementation, which was greater than $90 \%$ across tutors. Tutees' mathematics scores on proximal and distal measures exhibited moderate to substantial improvements. These findings add to an evidence-base suggesting students with EBD to be capable and effective cross-age tutors when provided with the appropriate training and supervision.

In regards to training, some improvements may be necessary for future iterations of instructional models requiring the training of students with EBD as cross-age tutors. Fidelity of implementation means were high across tutors during the 10 -weeks of intervention. These results demonstrated tutors' ability to effectively implement the tutoring procedures, but areas for improvement can be identified when fidelity rates are disaggregated by weekly means. Re-training sessions were required and provided for four of five tutors within the first 3-weeks of the intervention phase. There are multiple explanations for these initial, variable 
levels of implementation. First, the initial tutor training session may have been insufficient in some component. Findings related to increased fidelity rates after re-training sessions suggests basic modifications to the training protocol may facilitate higher, initial rates of implementation. One recommendation would be to provide more practice opportunities with instructional procedures within training sessions. Tutors may also benefit from additional practice/role-playing with other students (e.g., peers being trained as tutors) during tutor training. This feature could be provided in addition to initial practice/role-play opportunities with the teacher-trainer, where corrective feedback and reinforcement is provided to the tutor. Additionally, an overall increase in frequency and/or duration of initial tutor-training sessions may support the development and maintenance of required tutoring procedures and strategies.

\section{Behavioral Outcomes for Tutors with EBD}

Allen and Feldman (1973) proposed that when students with or at-risk for disabilities undertake the role of a cross-age tutor, the large discrepancy between that role and their typical student identity requires a transformation that produces "spillover" effects seen in the form of increases in academic skills, time on-task, classroom behavior, and positive attitudes towards school. This explanation connects to role theory, which proposes that the behavior of the individual is influenced by the role they inhabit or play (Thomas \& Biddle, 1966). In the context of this study, the theory proposes that when students undertake a given role (e.g., cross-age tutor, teacher), they adopt the attitudes or behaviors associated with the assumed role/identity (Turner, 2002). Thus, this theory provides a possible explanation for some behavioral improvement during the intervention phase and decreases in those same behaviors after the responsibility/role of being a tutor was removed (i.e., during maintenance phase). Although the data, across tutors, was variable during the maintenance phase, distal 
effects were found in improvements in externalizing risk status for two tutors. In these instances, the findings related to generalized behavioral improvements and decrease riskstatus for EBD align with previous research showing potential benefits of cross-age tutoring on students' non-academic skill areas such as general classroom behavior, on-task behavior, social skills, and peer relationships (Blake, Wang, Cartledge, \& Gardner, 2000). Considering the limited literature base, it is currently unclear if this intervention shows promise as a peermediated instructional model, or if potential benefits are available for students with specific, challenging behaviors/disabilities. Thus, further research in this area is suggested, specifically in the measurement of distal outcomes for tutors (both academically and behaviorally), which has been infrequently addressed in previous studies. Additionally, there are needs for research methodologies designed to directly assess the potential impact of tutor training and tutor implementation on tutors' academic, social, and behavioral skills in generalized settings (i.e., outside of the tutoring environment; Watts, Bryant, \& Carroll, 2019).

\section{Limitations}

Caution must be used in generalizing the results of brief interventions due to their low external validity (Slavin, 2008). Two main limitations need to be considered when interpreting the results of this study. First, the uniqueness of the design implemented to evaluate outcomes for two distinct populations of students with disabilities poses limitations. One challenge in utilizing a co-occurring multiple baseline design across two sets of participant groups is the intertwined intervention schedule, that is, when the independent variable (i.e., tutoring program) is introduced to the tutee, it must also be introduced to the tutor (i.e., tutoring sessions are attended by the dyad). Therefore, a decision must be made as to which of the participant's baseline data (i.e., tutees or tutors) will be utilized in 
determining when the intervention will be introduced. For this study, a rationale was

provided for utilizing the tutees' TEMI-AC total scores as the primary data set for evaluating the stability of the baseline phase, and therefore, determining when each dyad would be provided the intervention (i.e., provided tutor training and begin attending tutoring sessions). One potential issue with this arrangement occurs when tutee's baseline data quickly stabilizes in trend and level, providing inadequate time for the tutors' baseline data to stabilize before the intervention is introduced, therefore, making the interpretation of results more challenging.

Second, due to the components, structure, and delivery of the intervention (e.g., training tutors, implementation of number line board games, peer-mediated instruction), it is difficult to assess which component(s) was/were the primary mechanism(s) of change. For example, during tutoring sessions, the tutees were exposed to modeling, multiple practice opportunities, explicit feedback, number line board game materials/procedures, positive reinforcement, and attention from, and interactions with an older peer. Each of these components has evidence of supporting effective instruction and could have potentially assisted the development of early numeracy knowledge and skills. Therefore, although the intervention resulted in positive participant outcomes, the mechanism of change cannot be readily determined.

\section{Future Research}

There is still much to be evaluated for this instructional model in terms of replication/external validity, component analysis/dosage, measurement of tutor outcomes, implementers, methodological rigor, and potential benefits for other at-risk populations. Due to the innovative nature of this study, and considering the limited research, there is a need for replication of these methods and procedures to assess external validity. Furthermore, 
conducting a component analysis may assist in identifying the mechanisms of change within the model. Considerations for evaluating components of the cross-age tutoring model should include identifying the number of tutees effectively served one tutor, as well as the effect of dosage (i.e., frequency and duration) on participant outcomes. Determining the minimum dosage required to improve target skills would also assist in the standardization of the intervention's procedures as well as identify the model's utility for specific student needs. Considering the cross-age model's utility in providing supplemental instruction, identifying the effects of the intervention's duration on student outcomes may be beneficial for supporting its use as a booster/supplemental instructional practice for students at-risk.

\section{Implications for Practice}

Special education classrooms show a continuing demand for effective instructional techniques and arrangements that meet the needs of students with disabilities. Barriers to certain instructional models and interventions become compounded when cost(s) and/or feasibility are issues (e.g., staff/personnel requirements, necessary training; Bettini, Kimerling, Park, \& Murphy, 2015). Cross-age tutoring has shown promise of effectiveness and feasibility for practitioner implementation, and may be suitable for addressing the intensive needs of students with/at-risk for mathematics difficulties, while also providing tutors with EBD opportunities to practice and develop social and behavioral skills in an academic context (Watts, Bryant, \& Carroll, 2019).

Considering the evidence showing teachers and students are more likely to continue using the practice with fidelity when they perceive it to be effective or beneficial, the implications of this study's social validity findings are promising (Hawkins, Kroeger, Musti-Rao, Barnett, \& Ward, 2008). Furthermore, this intervention aligns with the development of special educator preparation programming that teaches and supports 
proactive, instead of reactive practices (e.g., timeout/isolation, removal/exclusion from general education setting) when working with students with EBD (Oliver \& Reschly, 2010).

This study adds to the groundwork for a future line of research in studying the effectiveness, feasibility, social validity, and related outcomes of an academic cross-age tutoring intervention delivered by students with EBD. 
References

Allen, V. L., and Feldman, R. S. (1973). Learning through tutoring: Low achieving children as tutors. Journal of Experimental Education, 42: 1-5.

Bettini, E., Kimerling, J., Park, Y., \& Murphy, K. M. (2015). Responsibilities and instructional time: Relationships identified by teachers in self-contained classes for students with emotional and behavioral disabilities. Preventing School Failure: Alternative Education for Children and Youth, 59(3), 121-128. doi:10.1080/1045988X.2013.859561

Blake, C., Wang, W. Q., Cartledge, G., \& Gardner, R. (2000). Middle school students with serious emotional disturbance serve as social skills trainers and reinforcers for peers with SED. Behavioral Disorders, 25(4), 280-298.

Clarke, B., Doabler, C. T., Kosty, D., Nelson, E. K., Smolkowski, K., Fien, H., \& Turtura, J. (2017). Testing the efficacy of a kindergarten mathematics intervention by small group size. AERA Open, 3(2), 2332858417706899. doi:10.1177/2332858417706899 Cook, B., Buysse, V., Klingner, J., Landrum, T., McWilliam, R., Tankersley, M., \& Test, D. (2014). Council for Exceptional Children: Standards for evidence-based practices in special education. TEACHING Exceptional Children, 46, 206-212. doi:101177/0040059914531389

Doabler, C. T., Clarke, B., Stoolmiller, M., Kosty, D., Fien, F., Smolkowski, K., \& Baker, S. K. (2017). Treatment intensity and instructional interactions: Exploring the black box of a tier 2 mathematics intervention. Remedial and Special Education, Advance online publication. doi:10.1177/0741932516654219

Drummond, T. (1994). The Student Risk Screening Scale (SRSS). Grants Pass, OR: Josephine County Mental Health Program.

Ginsburg, H. P. and Baroody, A. J. (2003). Test of Early Mathematics Ability-Third edition 
(TEMA-3). Austin, TX: PRO-ED.

Hawken, L. S., Bundock, K., Kladis, K., O’Keeffe, B., \& Barrett, C. A. (2014). Systematic review of the check-in, check-out intervention for students at risk for emotional and behavioral disorders. Education and Treatment of Children, 37, 635-658. doi: 10.1353/etc. 2014.0030

Hawkins, R. O., Kroeger, S. D., Musti-Rao, S., Barnett, D. W. and Ward, J. E. (2008), Preservice training in response to intervention: Learning by doing an interdisciplinary field experience. Psychol. Schs., 45, 745-762. doi:10.1002/pits.20339

Horner, R., Swaminathan, H., Sugai, G., \& Smolkowski, K. (2012). Considerations for the systematic analysis and use of single-case research. Education \& Treatment of Children, 35, 269-290. doi:10.1353/etc.2012.0011

Institute of Education Sciences. (2017). What works clearinghouse procedures and standards handbook (Version 4.0). Retrieved from https://ies.ed.gov/ncee/wwc/Docs/referenceresources/wwc_standards_handbook_v4.pdf

Jordan, N. C., Glutting, J., \& Ramineni, C. (2010). The importance of number sense to mathematics achievement in first and third grades. Learning and Individual Differences, 20, 82-88.

Jordan, N. C., Kaplan, D., Locuniak, M. N., \& Ramineni, C. (2007). Predicting first-grade math achievement from developmental number sense trajectories. Learning Disabilities Research and Practice, 22, 36-46.

Jordan, N. C., Kaplan, D., Ramineni, C., \& Locuniak, M. N. (2009). Early math matters: Kindergarten number competence and later mathematics outcomes. Developmental Psychology, 45(3), 850-867. doi:10.1037/a0014939

Kennedy, C. H. (2005). Single-case designs for educational research. Boston, MA: Allyn \& 
Bacon.

Kern, L. (2015). Addressing the needs of students with social, emotional, and behavioral problems: Reflections and visions. Remedial and Special Education, 36, 24-27. doi:10.1177/07419232514554104

Lane, K. L., \& Menzies, H. M. (2009). Student Risk Screening Scale for Early Internalizing and Externalizing Behavior (SRSS-IE). Retrieved from http://www.ci3t.org/screening\#srssie.

Lane, K. L., Oakes, W. P., Swogger, E. D., Schatschneider, C., Menzies, H., M., \& Sanchez, J. (2015). Student risk screening scale for internalizing and externalizing behaviors: Preliminary cut scores to support data-informed decision making. Behavioral Disorders, 40, 159-170. doi:10.17988/0198-7429-40.3.159

Laski, E. V., \& Siegler, R. S. (2007). Is 27 a big number? Correlational and causal connections among numerical categorization, number line estimation, and numerical magnitude comparison. Child Development, 78, 1723-1743. doi:10.1111/j.14678624.2007.01087.x

Lazerson, D. B. (2005). Detention home teens as tutors: A cooperative cross-age tutoring pilot project. Emotional \& Behavioural Difficulties, 10(1), 7-15. doi:10.1177/1363275205050881

Locuniak, M. N., \& Jordan, N. C. (2008). Using kindergarten number sense to predict calculation fluency in second grade. Journal of Learning Disabilities, 41, 451-459.

Mazzocco, M. M. M., Feigenson, L., \& Halberda, J. (2011). Impaired acuity of the approximate number system underlies mathematical learning disability (dyscalculia). Child Development, 82(4), 1224-1237. doi:10.1111/j.1467-8624.2011.01608.x. National Mathematics Advisory Panel. (2008). Foundations for success: The final report of the 
National Mathematics Advisory Panel. Washington, DC: U.S. Department of Education.

Okilwa, N. S. A., \& Shelby, L. (2010). The effects of peer tutoring on academic performance of students with disabilities in grades 6 through 12: A synthesis of the literature. Remedial and Special Education, 31(6), 450-463. doi:10.1177/0741932509355991

Oliver, R., \& Reschly, D. (2010). Special education teacher preparation in classroom management: Implications for students with emotional and behavioral disorders. Behavioral Disorders, 35(3), 188-199.

Ramani, G. B., \& Siegler, R. S. (2008). Promoting broad and stable improvements in lowincome children's numerical knowledge through playing number board games. Child Development, 79, 375-394. doi: 10.1111/j.1467-8624.2007.01131.x

Ramani, G. B., \& Siegler, R. S. (2011). Reducing the gap in numerical knowledge between low- and middle-income preschoolers. Journal of Applied Developmental Psychology, 32, 146-159. doi:10.1016/j.appdev.2011.02.005

Ramani, G. B., Siegler, R. S., \& Hitti, A. (2012). Taking it to the classroom: Number board games as a small group learning activity. Journal of Educational Psychology, 104, 661672.

Slavin, R. E. (2008). Perspectives on evidence-based research in education-What works? Issues in synthesizing educational program evaluations. Educational Researcher, 37(1), 5-14. doi:10.3102/0013189X08314117

Siegler, R. S., \& Ramani, G. B. (2008). Playing board games promotes low-income children’s numerical development. Developmental Science, 11, 655-661. doi:10.1111/j.14677687.2008.00714.x

Siegler, R. S., \& Ramani, G. B. (2009). Playing linear number board games—but not circular 
ones_-improves low-income preschoolers' numerical understanding. Journal of Educational Psychology, 101, 545-560.

Sugai, G., \& Horner, R. (2006). A promising approach for expanding and sustaining schoolwide positive behavior support. School Psychology Review, 35, 245-259.

Thomas, E. J., and Biddle, B. J. (1966). The nature and history of role theory. In Biddle, B. J., and Thomas, E. J. (eds.), Role Theory: Concepts and Research, Wiley, New York, pp. $3-20$.

Toll, S. W. M., Van der Ven, S. H. G., Kroesbergen, E. H., \& Van Luit, J. E. H. (2011). Executive functions as predictors of math learning disabilities. Journal of Learning Disabilities, 44, 521-532.

Turner, R. H. (2002). Role theory. In Turner, J. H. (ed.), Handbook of Sociological Theory (pp. 233-254). Kluwer, New York.

University of Texas System/Texas Education Agency. (2009). Texas Early Mathematics Inventory-AIM Checks. Austin, TX: University of Texas System/Texas Education Agency.

Van Luit, J. E. H., \& Schopman, E. A. M. (2000). Improving early numeracy of young children with special educational needs. Remedial and Special Education, 21, 27-40.

Watts, G. W., Bryant, D. P., \& Carroll, M. L. (2019). Students with emotional-behavioral disorders as cross-age tutors: A synthesis of the literature. Behavioral Disorders, 44(3), 131-147. doi:10.1177/0198742918771914 
Table 1

Tutees' Demographic and Pre-test Information.

\begin{tabular}{|c|c|c|c|c|c|}
\hline & Tutee 1 & Tutee 2 & Tutee 3 & Tutee 4 & Tutee 5 \\
\hline Age (years-months) & $5-3$ & $5-2$ & $5-5$ & $5-3$ & $5-0$ \\
\hline Grade & $\mathrm{K}$ & $\mathrm{K}$ & $\mathrm{K}$ & $\mathrm{K}$ & K \\
\hline Gender & M & M & M & M & M \\
\hline Race/Ethnicity & $\begin{array}{l}\text { African- } \\
\text { American }\end{array}$ & Hispanic & Caucasian & Caucasian & Caucasian \\
\hline $\begin{array}{l}\text { IEP/ } \\
\text { Disability status }\end{array}$ & $\begin{array}{l}\text { None/ } \\
\text { At-risk }\end{array}$ & $\begin{array}{l}\text { None/ } \\
\text { At-risk }\end{array}$ & $\begin{array}{l}\text { None/ } \\
\text { At-risk }\end{array}$ & $\begin{array}{l}\text { None/ } \\
\text { At-risk }\end{array}$ & $\begin{array}{l}\text { None/ } \\
\text { At-risk }\end{array}$ \\
\hline Free/Reduced lunch & $\mathrm{Y}$ & $\mathrm{Y}$ & $\mathrm{Y}$ & $\mathrm{Y}$ & $\mathrm{N}$ \\
\hline $\begin{array}{l}\text { Pre-test } \\
\text { TEMA-3 }\end{array}$ & 77 & 77 & 80 & 75 & 72 \\
\hline
\end{tabular}


Table 2

Tutors' Demographic and Pre-test Information.

\begin{tabular}{|c|c|c|c|c|c|c|}
\hline \multicolumn{3}{|c|}{ Tutor 1} & Tutor 2 & Tutor 3 & Tutor 4 & Tutor 5 \\
\hline \multicolumn{2}{|c|}{ Age (years-months) } & $10-9$ & $11-6$ & $10-5$ & $12-2$ & $11-0$ \\
\hline \multicolumn{2}{|l|}{ Grade } & 5 & 6 & 5 & 6 & 5 \\
\hline \multicolumn{2}{|l|}{ Gender } & M & M & M & M & M \\
\hline \multicolumn{2}{|c|}{ Race/Ethnicity } & Caucasian & Caucasian & Caucasian & Caucasian & Caucasian \\
\hline \multicolumn{2}{|c|}{ IEP disability category } & EBD & $\begin{array}{l}\text { LD \& at- } \\
\text { risk for } \\
\text { EBD }\end{array}$ & EBD & $\begin{array}{l}\text { LD \& at- } \\
\text { risk for } \\
\text { EBD }\end{array}$ & EBD \\
\hline \multicolumn{2}{|c|}{ Free/Reduced lunch } & $\mathrm{Y}$ & $\mathrm{N}$ & $\mathrm{Y}$ & $\mathrm{Y}$ & Y \\
\hline \multirow{2}{*}{$\begin{array}{l}\text { Pre-test } \\
\text { SRSS-IE } \\
\text { Scores } \\
\text { (Risk- } \\
\text { status) }\end{array}$} & SRSS-E7: & $\begin{array}{c}10 \\
\text { (High) }\end{array}$ & (High) & $\begin{array}{c}17 \\
\text { (High) }\end{array}$ & $\begin{array}{c}13 \\
\text { (High) }\end{array}$ & $\begin{array}{c}15 \\
\text { (High) }\end{array}$ \\
\hline & SRSS-I5: & $\begin{array}{c}4 \\
\text { (High) }\end{array}$ & $\begin{array}{c}8 \\
\text { (High) }\end{array}$ & $\begin{array}{c}13 \\
\text { (High) }\end{array}$ & $\begin{array}{c}13 \\
\text { (High) }\end{array}$ & $\begin{array}{c}11 \\
\text { (High) }\end{array}$ \\
\hline
\end{tabular}

Note. $\mathrm{M}=$ male; IEP = Individualized Education Program; EBD = Emotional-behavioral disorder; LD = learning disability; $\mathrm{Y}=$ yes; $\mathrm{N}=$ no; SRSS-IE = Student Risk Screening ScaleInternalizing and Externalizing (Drummond, 1994; Lane \& Menzies, 2009); SRSS-E7 = externalizing subtest; SRSS-I5 = internalizing subtest; Cut scores = high-risk (E7: 9-21; I5: 415); moderate-risk (E7: 4-8; I5: 2-3) 
Table 3

Effects by Student and Phase.

\begin{tabular}{|c|c|c|c|c|c|}
\hline Tutees & $\begin{array}{c}\text { Phase compared } \\
\text { to baseline }\end{array}$ & $\begin{array}{c}\text { PND \% } \\
(T E M I-A C)\end{array}$ & Tutors & $\begin{array}{c}\text { Phase compared } \\
\text { to baseline }\end{array}$ & $\begin{array}{l}\mathrm{PND} \% \\
(\mathrm{CICO})\end{array}$ \\
\hline \multirow[t]{2}{*}{ Tutee 1} & Intervention & 70 & Tutor 1 & Intervention & 90 \\
\hline & Maintenance & 100 & & Maintenance & 100 \\
\hline \multirow[t]{2}{*}{ Tutee 2} & Intervention & 70 & Tutor 2 & Intervention & 70 \\
\hline & Maintenance & 100 & & Maintenance & 100 \\
\hline \multirow[t]{2}{*}{ Tutee 3} & Intervention & 100 & Tutor 3 & Intervention & 66.7 \\
\hline & Maintenance & $\mathrm{N} / \mathrm{A}$ & & Maintenance & 0 \\
\hline \multirow[t]{2}{*}{ Tutee 4} & Intervention & 90 & Tutor 4 & Intervention & 30 \\
\hline & Maintenance & 100 & & Maintenance & 0 \\
\hline \multirow[t]{2}{*}{ Tutee 5} & Intervention & 10 & Tutor 5 & Intervention & 70 \\
\hline & Maintenance & 100 & & Maintenance & 0 \\
\hline \multicolumn{2}{|c|}{ Intervention Mean (SD) } & $68(34.9)$ & Inte & tion Mean (SD) & $65.3(21.8)$ \\
\hline \multicolumn{2}{|c|}{ Maintenance Mean (SD) } & $100(0)$ & Mai & ance Mean (SD) & $40(54.8)$ \\
\hline
\end{tabular}

Note. $\mathrm{PND}=$ percentage of nonoverlapping data; $\mathrm{SD}=$ standard deviation 
Table 4

Tutees'Pre-/Post-Test TEMA-3 Scores

\begin{tabular}{cccc} 
Tutees & TEMA-3 Pre & TEMA-3 Post & Pre-/Post- Change \\
\hline Tutee 1 & 77 & 98 & +21 \\
Tutee 2 & 77 & 89 & +12 \\
Tutee 3 & 80 & N/A & \\
Tutee 4 & 75 & 95 & +20 \\
Tutee 5 & 72 & 90 & +18 \\
\hline $\begin{array}{c}\text { Mean } \\
\text { (SD) }\end{array}$ & 76.2 & 93 & +17.8 \\
& $(2.9)$ & $(4.2)$ & $(4.0)$
\end{tabular}

Note. TEMA-3 = Test of Early Mathematics Ability-3: Standard Scores (Ginsburg \& Baroody, 2003); SD = standard deviation 
Table 5

Tutors' Pre-/Post-Intervention SRSS-IE Scores and Risk Status.

\begin{tabular}{lcc|cc|cc|cc}
\hline & \multicolumn{2}{c}{$\begin{array}{c}\text { SRSS-IE } \\
\text { Pre }\end{array}$} & $\begin{array}{c}\text { E7 } \\
\text { Tutors }\end{array}$ & $\begin{array}{c}\text { I5 } \\
\text { (Extrn.) }\end{array}$ & $\begin{array}{c}\text { E7 } \\
\text { (Intrn.) }\end{array}$ & $\begin{array}{c}\text { I5 } \\
\text { (Extrn.) }\end{array}$ & $\begin{array}{c}\text { Risk Status } \\
\text { Pre }\end{array}$ & \multicolumn{2}{c}{$\begin{array}{c}\text { Risk Status } \\
\text { Post }\end{array}$} \\
\hline Tutor 1 & 10 & 4 & 8 & 6 & $\mathrm{H}$ & $\mathrm{H}$ & $\mathrm{M}$ & $\mathrm{H}$ \\
(Extrn.) & $\begin{array}{c}\text { Intrn. } \\
\text { (Intrn }\end{array}$ & $\begin{array}{c}\text { I5 } \\
\text { (Extrn.) }\end{array}$ & (Intrn.) \\
Tutor 2 & 11 & 8 & 7 & 8 & $\mathrm{H}$ & $\mathrm{H}$ & $\mathrm{M}$ & $\mathrm{H}$ \\
Tutor 3 & 17 & 13 & 15 & 12 & $\mathrm{H}$ & $\mathrm{H}$ & $\mathrm{H}$ & $\mathrm{H}$ \\
Tutor 4 & 13 & 13 & 6 & 12 & $\mathrm{H}$ & $\mathrm{H}$ & $\mathrm{H}$ & $\mathrm{H}$ \\
Tutor 5 & 15 & 11 & 13 & 9 & $\mathrm{H}$ & $\mathrm{H}$ & $\mathrm{H}$ & $\mathrm{H}$ \\
\hline Mean & 13.2 & 9.8 & 9.8 & 9.4 & & & & \\
(SD) & $(2.6)$ & $(3.4)$ & $(3.5)$ & $(2.3)$ & & & & \\
\hline
\end{tabular}

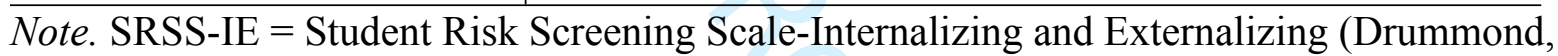
1994; Lane \& Menzies, 2009); E7 = externalizing subtest; I5 = internalizing subtest; SD = standard deviation; Cut scores: $\mathrm{H}=$ high-risk (E7: 9-21; I5: 4-15); $\mathrm{M}=$ moderate-risk (E7: 4-8; I5: $2-3$ ) 
Figure 1

Tutees' TEMI-AC Total Scores by Week.

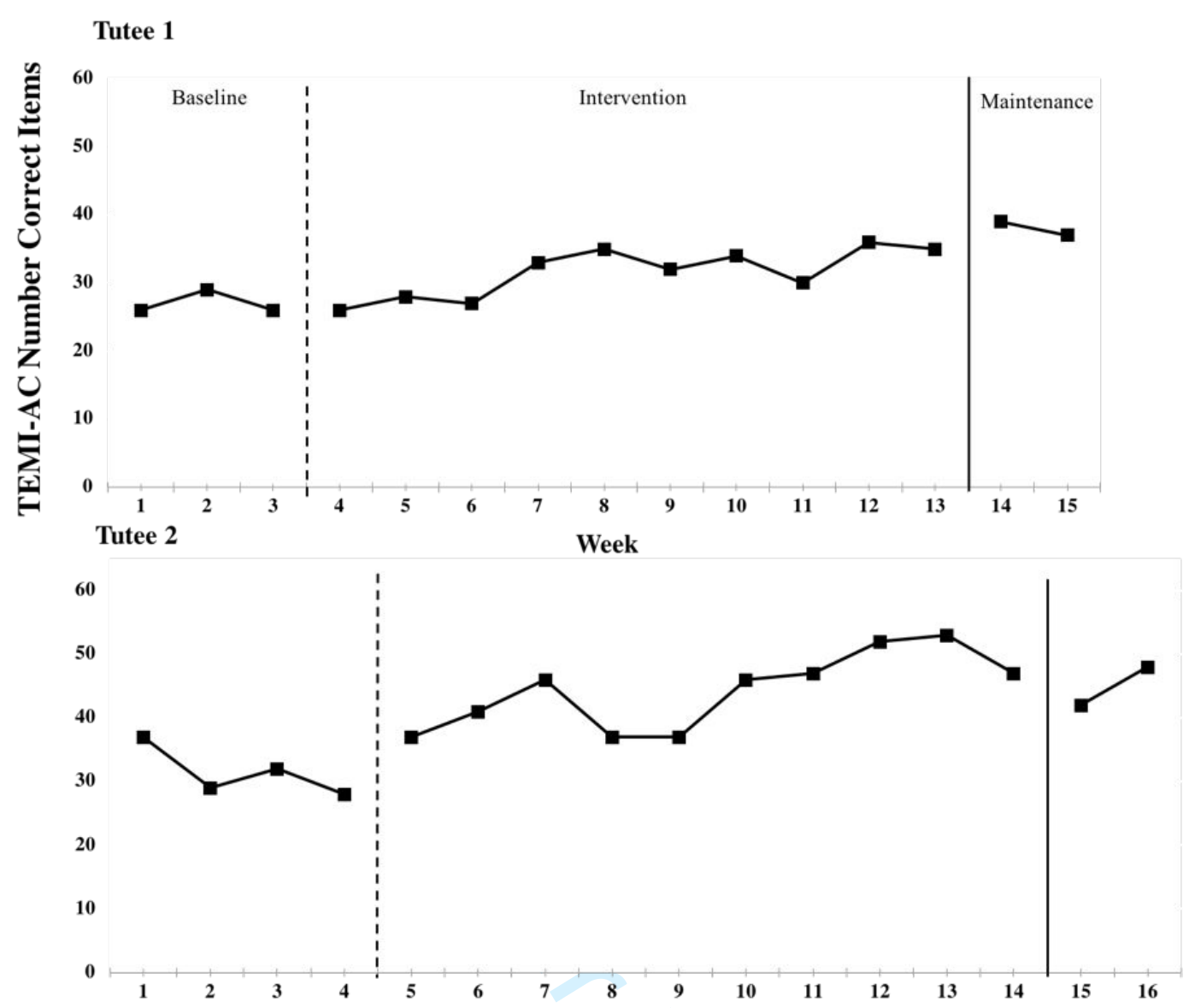

Tutee 3
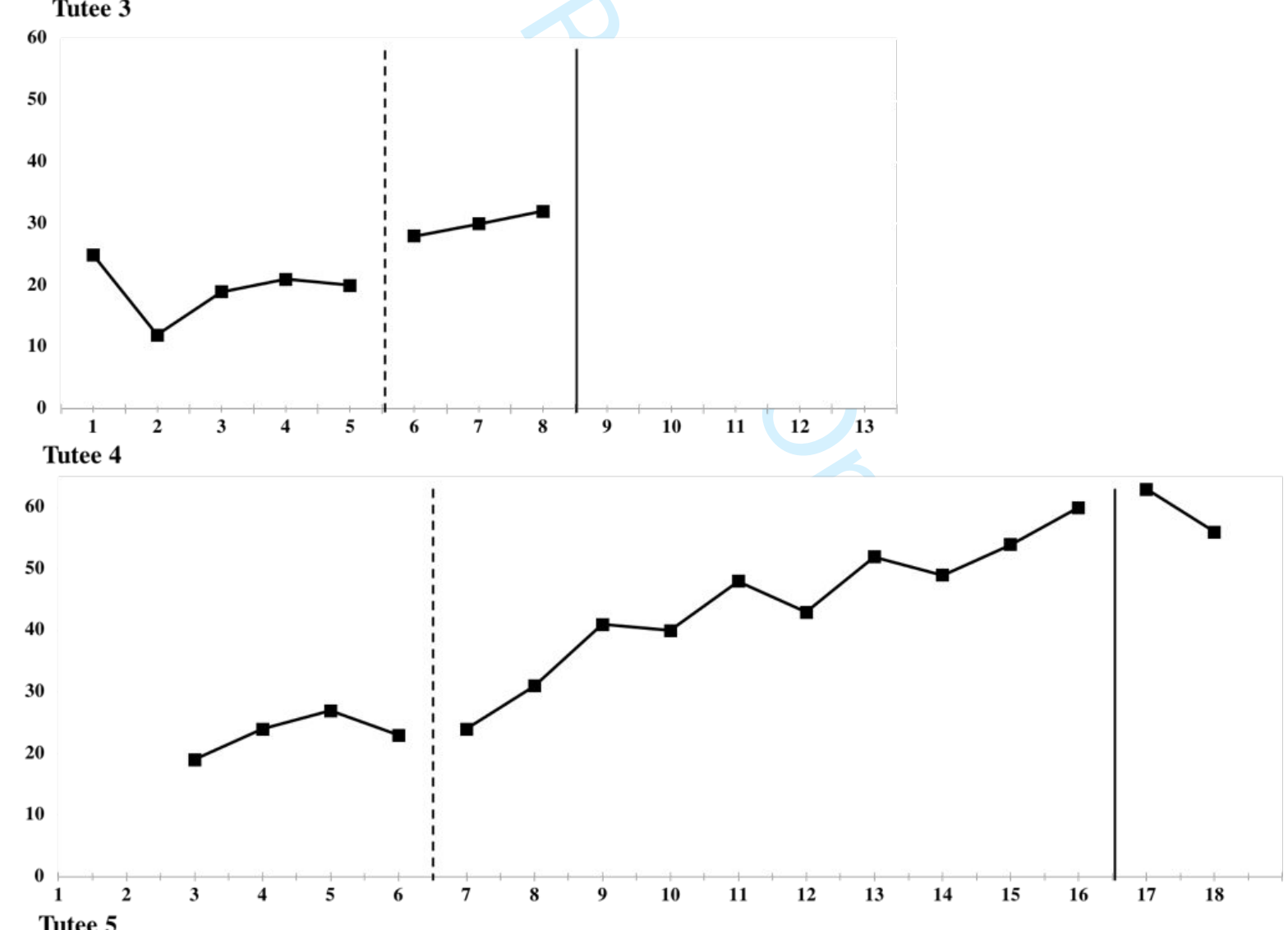
Tutee 5

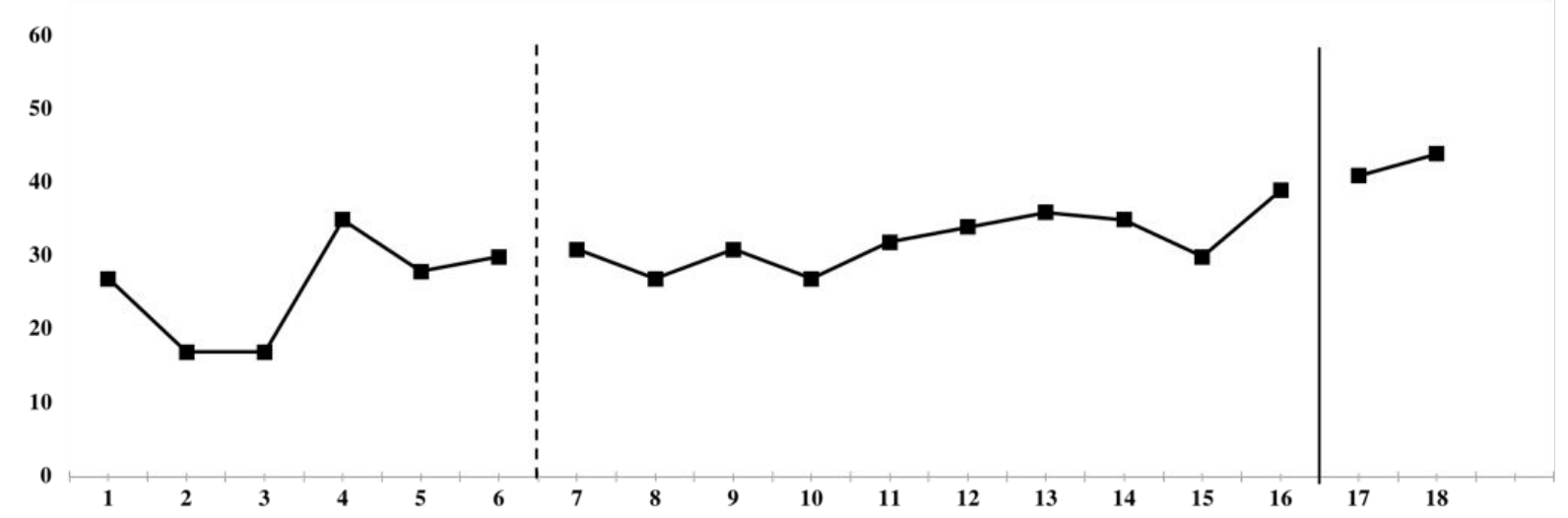


Figure 2

Tutors' CICO Behavioral Points by Week.
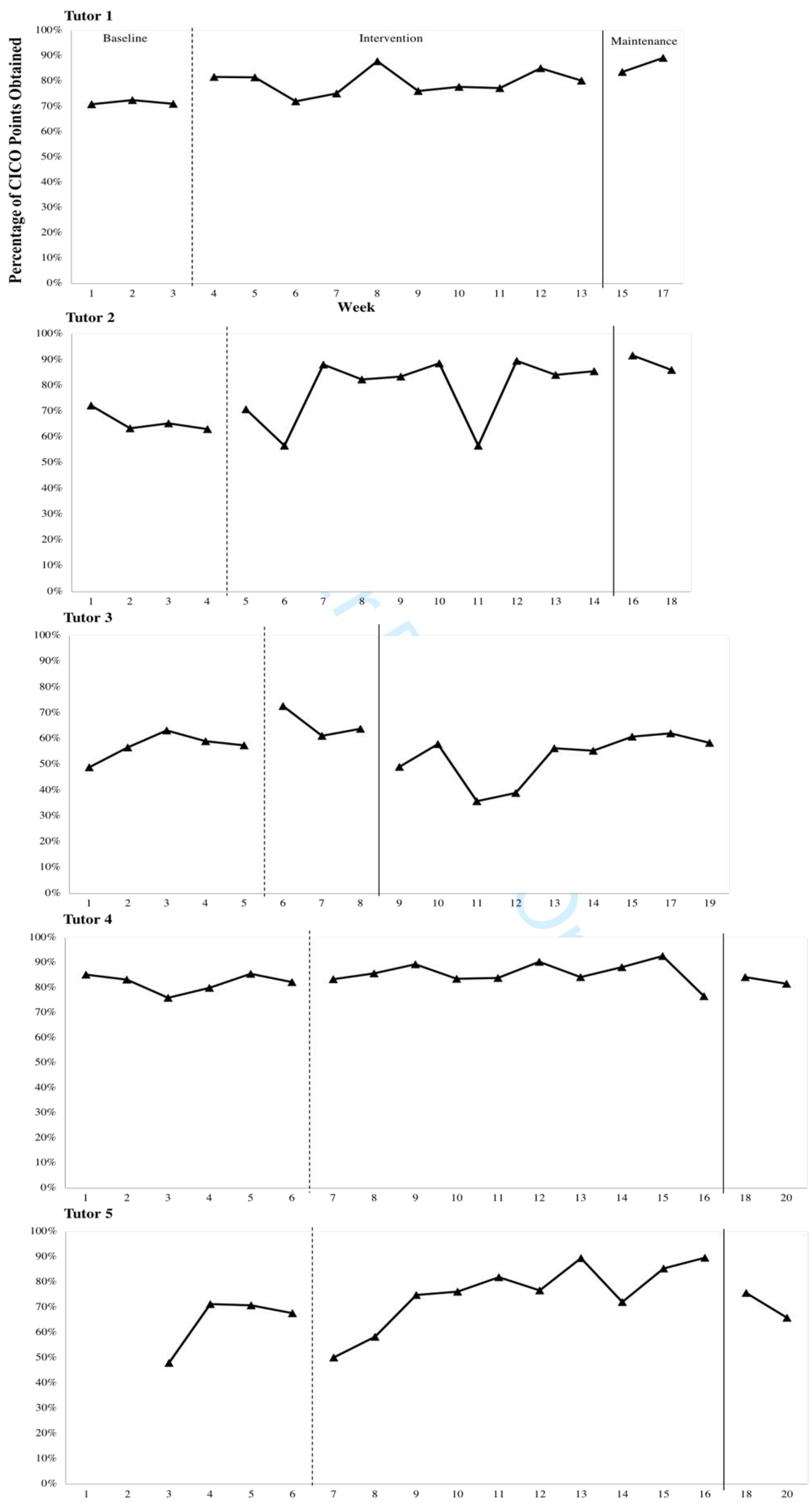